\title{
Evaluating the customers' dining attitudes, e-satisfaction and continuance intention toward mobile food ordering apps (MFOAs): evidence from Bangladesh
}

\author{
Md. Al Amin
}

Department of Marketing,

Bangabandhu Sheikh Mujibur Rahman Science and Technology University, Gopalgonj, Bangladesh

Md. Shamsul Arefin

Department of Management Studies,

Bangabandhu Sheikh Mujibur Rahman Science and Technology University, Gopalgonj, Bangladesh

Nayeema Sultana

Department of Business Administration, East West University, Dhaka, Bangladesh

Md. Rakibul Islam

Department of Management Studies,

Bangabandhu Sheikh Mujibur Rahman Science and Technology University,

Gopalgonj, Bangladesh, and

Israt Jahan and Ayeasha Akhtar

Department of Marketing,

Bangabandhu Sheikh Mujibur Rahman Science and Technology University,

Gopalgonj, Bangladesh

\begin{abstract}
Purpose - This study was designed to specifically explore confirmation and perceived usefulness associated with mobile food ordering apps (MFOAs) in consideration of their impacts upon attitudes, satisfaction and intention to continuously use.

Design/methodology/approach - The research utilized the convenience sampling to gather data from 250 respondents having prior experience with MFOAs during COVID-19 pandemic period in Bangladesh. The Structural Equation Modeling technique was applied to analyze the data using SmartPLS 3 software.

Findings - This study's results showed that customers' perceived confirmation and usefulness were significant in determining their dinning attitudes. Besides, customers' dining attitudes were positively related to e-satisfaction. Finally, the customers' continuance intention to use MFOAs was significantly influenced by their e-satisfaction.
\end{abstract}

(C) Md. Al Amin, Md. Shamsul Arefin, Nayeema Sultana, Md. Rakibul Islam, Israt Jahan and Ayeasha Akhtar. Published in European Journal of Management and Business Economics. Published by Emerald Publishing Limited. This article is published under the Creative Commons Attribution (CC BY 4.0) licence. Anyone may reproduce, distribute, translate and create derivative works of this article (for both commercial and non-commercial purposes), subject to full attribution to the original publication and authors. The full terms of this licence may be seen at http://creativecommons.org/licences/by/4.0/ legalcode
Evaluating the customers' dining attitudes 
EJMBE 30,2

Research limitations/implications - Restaurants managers should focus on online sales through MFOAs during the pandemic period since social distancing is a key strategy to manage COVID-19. Customers should be assured that the safety measures are undertaken while delivering the food.

Originality/value - This study incorporated the expectation-confirmation theory and technology acceptance model and tested it in the context of MFOAs.

Keywords E-satisfaction, Confirmation, Dining attitudes, Continuance intention, Mobile food ordering apps (MFOAs), Restaurants

Paper type Research paper

\section{Introduction}

Owing to the massive growth of information communication technology (ICT) and smartphones, smart technologies and mobile application (app) software have become an essential part of modern life (Baabdullah et al., 2019; Koiri et al., 2019; Tang, 2019; Shareef et al., 2012; Shah et al., 2020). The mobile apps have also shifted people's lifestyles and society at large (Ray et al., 2019; Xu and Huang, 2019). Mobile food ordering apps (MFOAs) have been considered one of the most popular mobile apps in Bangladesh since its inception in 2013. For example, Pathao Foods has 7,000 registered Bangladeshi restaurants, while Sohoz Food has 6,000 restaurants, and Foodpanda has 6,500 restaurants until 2019 (Hasan, 2020). Bangladeshi restaurants have started to consider mobile commerce applications as new mechanisms to attract new customers and retain the existing customers in the intense competitive restaurants' sector, comprising more than 30,000 restaurants (Khan and Khan 2020). It is also possible to categorize the services provided by various MFOAs as providing orders, monitoring, payment, and tracking facilities. Still, they are not responsible for the actual preparation of foods (Pigatto et al., 2017). On the other end, customers can search for a restaurant, compare offers of alternative restaurants, purchase and provide reviews through mobile apps (Carlson et al., 2019; Thakur, 2014; Yang, et al. 2016, 2017).

With the introduction of HungryNaki, an online food delivery service provider, different MFOAs were expanding in Bangladesh since 2013. In contrast, similar services in other parts of the world began around the 2000s. Bangladesh is a densely populated nation of 162 million people, with 1,251 people residing per square mile (UN, 2020). There are 165.34 million mobile phone subscribers, of which 94.24 million are Internet subscribers (BTRC, 2020). About 50\% of the population is under 25 of age, mostly fascinated with fast food and restaurants. The MFOAs are becoming popular in Bangladesh because people's lifestyles are changing with higher buying capability, increased busy hours, and enhanced dependence on technology, leading them to take readymade foods. The growing number of restaurants has also played a role in pushing the demand for online food service. All of these attributes have stimulated MFOA growth in Bangladesh. According to several industry insiders of Bangladesh, the total daily delivery was 25,000 orders per day in 2019 on average (Future Startup 2020). The overall current market size for food delivery is $\$ 10$ million in 2019 , and it could grow to over $\$ 5$ billion by 2025 (Future Startup, 2020).

The surge of online orders and delivery has been witnessed in this COVID-19 pandemic situation (Hospitality Insights, 2020). An online food delivery survey among 3,606 consumers in UK, Italy, Brazil, and South Korea reveals that COVID-19 has a positive impact on frequency and spending on online food delivery and the majority of new users $(57 \%)$ are likely to use it again (Citi Velocity, 2020). In the pandemic period, people are likely to avoid social cohesion and gathering. Gössling et al. (2020) discuss the impact of COVID-19 on tourism, including the food and beverage sector. Social distancing will have to remain a key strategy to manage COVID-19 in many countries for several months; it can be expected that restaurants will face problems recovering, specifically as they usually have limited liquidity and small profit margins. Where restaurants are allowed to stay open for takeaway 
customers, this is an operational alternative that requires limited staff. Many smaller places, including cafés, may have decided to stay closed, as diminished customer flows do not make it possible to operate at a plus. The initial easing of social distancing is likely to advantage fast food over fine-dining restaurants. Further research on the impact of COVID-19 on mobile ordering apps will be useful as safe distancing could mean more consumers using mobile apps to order food delivery rather than visiting restaurants. Bangladesh has more than 204,525 infected cases as at July 19, 2020 (Worldometers 2020).

This study aims to examine how usefulness, expectations' confirmation (EXPC), dinning attitude (D-ATT) and satisfaction (E-SAT) influence customers' continuance intention (CI) using MFOAs. This study focuses on customers' post-adoption behavior based on the expectation-confirmation theory (ECT) (Bhattacherjee, 2001). It was intended to explain users' CI after their initial adoption and use of a specific information system. In addition to the ECT model, customers' dining attitude is incorporated from the technology acceptance model (TAM) (Davis et al., 1989). The sustainability of the MFOAs depends on how much they serve their existing consumers' needs and expectations (Ray et al., 2019). Customers prefer using mobile apps in ordering foods because of their convenience and speed. Therefore, it is crucial to identify why customers use MFOAs by understanding relevant factors influencing customers' continued use intention. The previous studies primarily focused on the segmented view of MFOAs adoption and its impact on customers' CI to use (Alalwan, 2020; Okumus and Bilgihan, 2014; Cho et al., 2019; Izzati, 2020). Addressing this gap, this study develops and examines a holistic model by incorporating usefulness, confirmation, attitude, e-satisfaction and continuance intention to use MFOAs in the Bangladeshi context. Besides, the impact of confirmation on attitude, e-satisfaction, and continuance intention to use MFOAs is further investigated and is one of the unique contributions of this study.

Researchers identified a variety of factors that affect the user's selection and continuance intention to use MFOAs. However, few studies have attempted to employ dining attitudes in the context of MFOAs. Grounding on TAM (Davis et al., 1989), we further argue that user's dining attitudes toward MFOAs plays a crucial role in explaining their satisfaction and continuance intention to use. There has been little research investigating usefulness, confirmation, attitudes, and satisfaction simultaneously in the context of MFOAs. More importantly, to the best of our knowledge, the ECT and TAM have not been employed combinedly to explain users' continuance intention in relation to MFOAs. Thus, this study intended to integrate ECT and TAM in the context of MFOAs.

The present study focuses on the gap mentioned earlier by examining the factors that impact the use of MFOAs in Bangladesh. It is essential to understand the underlying variables behind the use of MFOAs for three main reasons. First, it is well known that the food industry is a rapidly growing sector with a revenue estimate of around US $\$ 137.6$ billion by 2023 (Statista Report, 2018). Despite this vast potential, however, no prior study has investigated the impact of confirmation and usefulness on customers' attitudes, satisfaction, and intention to use MFOAs. We argue that understanding the impact of confirmation will provide new insight into the current literature of MFOAs. Second, this study will allow us to understand better consumers' perspectives in culturally diverse countries like Bangladesh. The previous study has articulated to conduct an empirical study in culturally diverse countries (Yeo et al., 2017) with a large sample. Most of the prior studies examined based on culturally similar countries and small samples (See-Kwong et al., 2017; Suhartanto et al., 2019; Yeo et al., 2017). Third, since the data were collected in the pandemic period from Bangladesh, this study will provide an understanding of the factors that influence customers' attitude, satisfaction, and continuance intention in an unusual situation that might intensify the usage. Due to customers' preferences to maintain social distancing in the pandemic situation, the service providers of MFOAs continue its delivery services with limited resources. 
EJMBE 30,2
The next part of the paper discusses the theoretical development and research hypotheses. Then, the subsequent part covers the methodology, followed by the empirical results and discussion elaborating on the theoretical contributions and practical implications. Finally, the paper concludes with limitations and future research implications.

\section{Literature review}

MFOA refers to the mobile-based system by which customers can order foods through mobile and appropriate application systems. While MFOAs systems have become common among the customers around the world, the academic interests in the study of MFOAs are still at its initial level (Okumus and Bilgihan, 2014; Alalwan, 2020). Recent studies have shown a keen interest in exploring the adoption of MFOAs among consumers. For example, Pigatto et al. (2017) conducted a qualitative study that sought to discover critical aspects that promoted MFOAs adoption of Brazilian, which signifies the usability, content, and functionality in the usage of MFOAs.

Prior research on MFOAs examined the numerous drivers of the user acceptability of MFOAs grounding on several theoretical foundations. The most prominent theory in the field of MFOAs acceptance is the TAM. Okumus and Bilgihan (2014) found that perceived usefulness, perceived enjoyment, social norms, ease of use and self-efficacy are the main predictors of a consumer's willingness to use MFOAs. Okumus et al. (2018) examined consumers' willingness to use mobile diet apps based on the Unified Theory of Acceptance and Use of Technology (UTAUT). They found that effort expectancy, social influence, and performance expectancy are important predictors of consumers' willingness to use. Moreover, Yeo et al. (2017) examined the Contingency Framework and Extended Model of IT Continuance. They found the support of the structural relationships of convenience motivation, post-usage usefulness, hedonic motivation, price saving orientation, time-saving orientation, prior online purchase experience, consumer attitude and behavioral intention towards online food delivery services.

Moreover, several researchers have considered consumers' attitudes as an essential variable toward MFOAs. In China, Cho et al. (2019) identified that consumers' attitudes and perceived value toward food delivery apps were significantly influenced by the level of trust, product verity, and design, and the customer perceptions of differences on these apps were observed between single-person and multi-person families. Alagoz and Hekimoglu (2012) have focused that factors like innovativeness, trust, and usefulness shaped consumers' attitudes towards online food delivery. Several researchers have focused on the outcomes of using MFOAs satisfaction, namely, customer conversion and customer experience. Wang et al. (2019) have proposed a model based on the IS success model predicting the critical outcomes of consumers' usage of mobile catering applications. They have found that when consumers perceive adequate quality in terms of services, system, product, and information, they create positive value towards mobile catering apps. Moreover, in Southern Taiwan Spyridou (2017) found perceived service quality is considered as one of the important determinants to predict CI (customer revisiting intention). Additionally, Kapoor and Vij (2018) found relevant evidence concerning the impact of mobile app features, including information design, visual design, collaboration design, and navigational design on the level of consumer conversion. For understanding the impact of customers' perception of the usefulness and confirmation on consumer's attitude, satisfaction, and continued intention to use, further research is needed to explore the key aspects that may impede or support effective implementation of MFOAs in South Asian context, Bangladesh. 


\section{Conceptual framework}

Over the last few decades, one of the most important research subjects is identifying the underlying factors that impact the continued usage of information systems (IS). Previous studies confirmed the variables, such as expectation, confirmation and satisfaction (e.g. Bhattacherjee, 2001 and Qazi et al., 2017), perceived usefulness and ease of use (e.g. Karahanna et al., 1999), and habit (e.g. Alalwan, 2020), have all been examined to better predict users' continued information system use in various contexts. Drawing on the expectation-confirmation theory (ECT) (Oliver, 1980), Bhattacherjee (2001) introduced a theoretical model demonstrating the continuance of the information system. The theory emphasizes the impact of the user's expectation, and subsequent acceptance of the use of an IS on their satisfaction, and perceived usefulness, which ultimately influences IS continuance intention. Different IS literature adopted and expanded the ECT model, including several variables such as perceived playfulness (Lin et al., 2005), habit (Limayem and Cheung, 2008) and resource quality (Joo and Choi, 2016). Despite the ECT's benefits as a research model, it has not been widely adopted in the MFOAs system context yet. This study integrated TAM and ECT model in the context of MFOAs.

\subsection{Customer expectation's confirmation and dinning attitudes}

Confirmation refers to the users' perception of the expected benefits of MFOAs' use and its actual performance (Bhattacherjee, 2001). Bhattacherjee (2001) claimed that confirmation positively affects perceived satisfaction, as it implies the realization of the expected benefits of information system use. Bhattacherjee (2001) suggested that confirmation had a positive effect on perceived satisfaction, as it indicated the anticipated value of information system utilization.

EXPC is the beliefs of customers regarding how they judge or evaluate a product, service, or technology artifact in comparison to their expectations (Oliver, 1977 and Kim, 2010). According to Oliver (1988) is "the summary psychological state resulting when the emotion surrounding disconfirmed expectations is coupled with a consumer's prior feelings about the consumer experience." Attitudes refer to the customers' overall reaction about performing a specific behavior in terms of particular device and technology usage (Ajzen, 1991). When the actual outcome of MFOAs exceeds customer expectations, customers are more likely to be satisfied and use those apps (Trivedi et al., 2018). Most of the time, customer perceptions are shaped by the customers' past experiences and determined their intention about the continuous use of MFAOs (Shaw, 2016). The number of times customers remain satisfied with the apps that the number of times customer trends to use them (Mundy, 2018). Customers' confirmations may positively affect the dinning of their attitudes to using MFOAs when the technology's evaluations match their specific expectations.

Contrary to $n$ time, the customers are more dependent on the MFOAs in the COVID-19 pandemic period when the maintenance of social distancing has become or as an essential part of everyone's life due to confined situations. Customers' confirmation of their preferred service might be more favorable towards MOFAs in the pandemic period. Therefore, MOFAs can be alternative media to maintain safe distancing (adapting to a new normal situation) to customers to order food rather than visiting the restaurant physically. To the best of our knowledge, no research was found to determine the relationship between confirmation and attitudes. Thus, to measure the impact of EXPC on D-ATT to use MFOAs in an emerging economy and culturally diverse country like Bangladesh MFOAs increasingly due to any confirmed situations has become necessary. Hence, we posit the following hypothesis:

H1. Customers' Confirmation has a positive relationship with dining attitudes.

\section{Evaluating the customers' dining attitudes}


EJMBE 30,2

\section{6}

\subsection{Perceived usefulness and dining attitudes}

$\mathrm{PU}$ is defined as "the degree to which a person believes that using a particular system would enhance his or her performance" (Davis, 1989). Following TAM (Davis, 1989), one of the most significant predictors of customers' attitudes to adopt new technology is PU. When customers believe that technological applications are useful and easy to use, they show positive attitudes toward using MFOAs (Kang and Namkung 2019). Moreover, Nguyen et al. (2019) demonstrated that the more customers think that MFOAs is useful, the more they build positive attitudes toward MFOAs. It is because FDA service providers may covey the apps' usefulness to educate customers and connect restaurants by providing useful features such as nutrition details, map directions, direct telephone calls, online coupons, and notifications. In addition, TRA model suggested that perceived usefulness significantly affects consumer's attitude. For example, in the context of online food delivery systems, PU was found as an antecedent of customers' attitudes and behavioral intention use (Alagoz and Hekimoglu, 2012). Although few studies confirmed the relationship between PU and D-ATT in ordering food, such as online food purchasing (Nguyen et al., 2019), online food ordering system (Alagoz and Hekimoglu, 2012), this study emphasizes the influence of PU on D-ATT in the pandemic period in the context of Bangladesh. Hence, we predict the following hypothesis:

H2. Perceived usefulness has a positive influence on dining attitudes.

\subsection{Dinning attitude and e-satisfaction}

E-satisfaction refers to the customer's contentment concerning other or her prior purchasing experience with a given electronic commerce firm (Alalwan 2020). Anderson and Srinivasan (2003, p. 125) define E-SAT "as the contentment of the customer concerning his or her prior purchasing experience with a given electronic commerce firm." Customer attitude is one of the elements to measure satisfaction as dining attitudes determine the customers through technology adoption (e.g. MFOAs). When customers' dining attitudes toward MFOAs are positive, they become more satisfied using MFOAs. More specifically, the positive attitudes towards MFOAs influence customers to be more satisfied with the service of MFOAs. Due to the social distancing and limited interaction with the service people are maintained in service transactions, customers may grow favorable attitudes and prefer MFOAs. Previous research paid less attention to investigate the relationship between dining attitudes and e-satisfaction of MFOAs. This study argues that customers' positive attitude toward MFOAs directly influences their e-satisfaction. Therefore, we posit the following hypothesis:

H3. Dining attitudes have a positive impact on e-satisfaction using MFOAs.

\subsection{Customer e-satisfaction and continuance intention}

Continuance intention means "to repurchase a product or continue service use" (Bhattacherjee, 2001, p. 353). If the service of MFOAs confirms customers' expectations, the customers are more likely to be delighted about their prior purchasing experiences and repeatedly order foods through MFOAs. Moreover, it can be constructed that E-SAT creates a unique position in the mind of a customer through positive perceptions regarding the value of a technology artifact. E-SAT has a causal effect on the intention to consistently use a particular IS (Bhattacherjee, 2001; Joo and Choi, 2016; Tran et al., 2019 and Lee et al. (2019). Few are known about how customers' e-satisfaction influences their continuance intention to use MFOAs. Recently, Alalwan (2020) found that e-satisfaction is positively related to customers' continuance intention to use MFOAs in Jordan. This study focused on the customers' e-satisfaction and continuance intention to use MFOAs in the pandemic period when customers are more likely to be cautious about maintaining the safety of their food and health. Thus, we propose the following hypothesis: 
H4. Customers' e-satisfaction has a positive impact on continuance intention to use MFOAs.

Figure 1 depicts the conceptual framework of the present study.

\section{Methodology}

\subsection{Research design}

The data were collected from the users of MFOAs of Bangladesh. In Bangladesh, MFOAs has become an integral part of urban users, mostly resided in large cities. The survey was conducted during the COVID-19 pandemic situation in Bangladesh. Due to the COVID-19 pandemic situation, the restaurants were allowed to keep operation and provide home delivery. While the social distance, home confinement or home quarantine was normed among the people, customers were likely to use MFOAs, and eventually, the service of MFOAs had been boosted. MFOA service providers had to maintain appropriate hygiene for safe food handling and delivery. The data has been collected during March and April 2020.

The MFOAs operators mostly provide their services in big cities in Bangladesh. HungryNaki, Uber Eats, Pathao Food, Food Panda and Sohoj Foods are the primary MFOAs services that operate within Dhaka city. A convenience sampling approach was taken in this study. The respondents reside in Dhaka city, the capital of Bangladesh, with 20 million people. As per Khan and Khan (2020), over 10,000 restaurants are operating in only Dhaka, and $60 \%$ of them are connected to at least one MFOAs. For the convenience of research, the respondents were chosen from the five major parts of Dhaka city, including Kalabagan, Gulshan, Banani, Puran Dhaka and Uttara. The respondents had at least one MFOA service experience and ordered through smartphones or computers from one of the MFOA services.

\subsection{Measurement items}

To ensure content validity, the survey instruments were reviewed by two faculty members from the first author's university, who have extensive experience in survey measurements. Based on their feedback, some of the wording of the items was modified. Twenty-five MFOA users were asked before the survey was released. Some minor wording has been modified from the pre-test. We used a five-point Likert scale from 1 (strongly disagree) to 5 (strongly agreed) to measure the items for the latent constructs. All items have been derived from existing researches. The study items were provided in Table A1. The questionnaire covered five identified constructs and demographic information. Items for Expectation Confirmation (EXPC) were adapted from Bhattacherjee (2001); Joo and Choi (2016) and Kim (2010). E-satisfaction (E-SAT) was validated using scale items extracted from Alalwan (2020), and Anderson and Sullivan (1993), Dining attitudes (D-ATT) were tested from items suggested by Cho et al. (2019). Perceived usefulness (PU) was tested with the items adapted from Okumus and Bilgihan (2014) and Davis et al. (1989)The items to measure continuous intention (CI) were extracted from Alalwan (2020), Faraoni et al. (2019) and Lee et al. (2019).

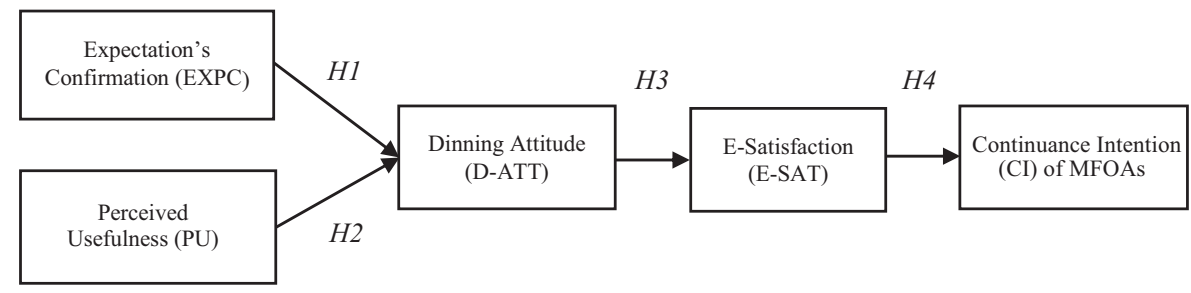

Evaluating the customers' dining attitudes

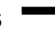


EJMBE 30,2

\section{8}

\begin{tabular}{|c|c|c|c|}
\hline & Variables & Number & Percentage \\
\hline & $\begin{array}{l}\text { Gender } \\
\text { Male } \\
\text { Female }\end{array}$ & $\begin{array}{l}137 \\
113\end{array}$ & $\begin{array}{l}56 \\
44\end{array}$ \\
\hline & $\begin{array}{l}\text { Age } \\
\text { Below } 24 \\
25-40 \\
40-55\end{array}$ & $\begin{array}{r}109 \\
61 \\
50\end{array}$ & $\begin{array}{l}54.5 \\
40 \\
5.5\end{array}$ \\
\hline & $\begin{array}{l}\text { Geographical Area(s) } \\
\text { Kalabagan } \\
\text { Gulshan } \\
\text { Banani } \\
\text { Puran Dhaka } \\
\text { Uttara }\end{array}$ & $\begin{array}{l}50 \\
50 \\
50 \\
50 \\
50\end{array}$ & $\begin{array}{l}20 \\
20 \\
20 \\
20 \\
20\end{array}$ \\
\hline & $\begin{array}{l}\text { Educational Background } \\
\text { Secondary level } \\
\text { Higher Secondary level } \\
\text { University level } \\
\text { Other }\end{array}$ & $\begin{array}{r}10 \\
40 \\
150 \\
50\end{array}$ & $\begin{array}{l}3 \\
19.5 \\
60 \\
17.5\end{array}$ \\
\hline & $\begin{array}{l}\text { Internet Users } \\
\text { Mobile Broadband } \\
\text { Wi-Fi- }\end{array}$ & $\begin{array}{r}80 \\
170\end{array}$ & $\begin{array}{l}40 \\
70\end{array}$ \\
\hline $\begin{array}{l}\text { Table } 1 \text {. } \\
\text { Demographic profile of } \\
\text { the respondents }\end{array}$ & $\begin{array}{l}\text { MFOAs } \\
\text { Food Panda } \\
\text { Pathaoo } \\
\text { Uber Eats } \\
\text { Others }\end{array}$ & $\begin{array}{r}100 \\
50 \\
30 \\
80\end{array}$ & $\begin{array}{l}40 \\
20 \\
10 \\
30\end{array}$ \\
\hline
\end{tabular}

\subsection{Data collection}

A questionnaire with demographic and measurement items was developed for this study. All the items in the questionnaire were initially been in English. The questionnaire was translated into Bengali using the back-translation process (Brislin, 1976). The respondents were sent the questionnaire via face-to-face and emails following the convenience sampling that is used by previous studies in food delivery (e.g. Cho et al., 2019). We sent a mail that includes a questionnaire and a cover letter to ensure the convenience of giving responses. An email to each respondent had been sent after two weeks from the prior email date with a request to fill up the questionnaire and send back the filled questionnaire document. Another two weeks had been given as a final try to the respondent who has failed to respond earlier. After two weeks, a final request had been delivered for the remaining respondents who did not respond to the survey. A total of 580 questionnaires were sent to the respondents. Among them, 277 responses were received. After discarding the incomplete responses, 250 respondents (43.10\% response rate) were taken for data analysis. Among them, $137(56 \%)$ were men, and 113 (44\%) were women. In terms of age, 109 respondents are below 24 years old, 61 respondents were between 25 and 40 ages, and 50 respondents were between 40 and 55 ages. Almost 10 respondents had a secondary level, 40 respondents had a higher secondary level, and 150 respondents had the university level of education. Most of the respondents (170 users) used Wi-Fi, and the rest of the respondents ( 80 users) used mobile data. Table 1 shows the demographic profile of the respondents. 


\subsection{Data analysis}

Structure equation modeling (SEM) was used to measure the relationship between the variables. Covariance-based SEM (CB-SEM) and Partial least square SEM (PLS-SEM) are the two categories of SEM. CB-SEM analyzes the relation between measured covariance-related variables. In contrast, PLS-SEM analyzes the dependent and independent variables depending on the projection and the prediction to optimize the explained variances (Wang et al., 2019). According to Wang et al. (2019), in maximizing the explained variances, PLS-SEM analyzes the dependent and independent variables based on the forecast and approximation. Based on a series of exogenous structures, PLS-SEM estimates the degree of changes in endogenous constructions. To measure structural relations and confirmatory factor analysis between study variables, we used SmartPLS 3.0 (Hair et al., 2017).

\subsection{Common method bias}

Since the data were collected from a single source, the possibility of CMB involves the measurement of both dependent and independent variables. Besides, for the minimization of the possible common method variance, this paper focused on both statistical and procedural remedies before and after data collection. We used the marker variable technique and Harman's single-factor test for determining the CMB. The principal component factor analysis revealed five factors with Eigenvalues greater than 1.0, while these factors accounted for $66 \%$ of the variance. Moreover, the first factor did not account for the majority of the variance $(19.53 \%)$. We can conclude that the CMB is not a concern for this study based on these findings (Podsakoff and Organ, 1986). We have conducted Lindell and Whitney's (2001) test that is suggested by various researchers. This test was designed to conduct a theoretically unrelated structure as a marker variable that examines the prospects for common method bias. An indicator of $\mathrm{CMB}$ can be evident when there is a high correlation between the marker variable and any other marker variable. We have utilized another survey variable as a marker (the information security), which is not used in this study. The correlation coefficients and $R^{2}$ between variables in the model and the marker show that the correlations were low (maximum $\left.R^{2}=0.041\right)$ - this suggests that common method bias was not a problem in our survey data.

\section{Results}

\subsection{Measurement model}

We evaluated construct reliability, composite reliability, convergent validity and discriminant validity following procedures suggested by Hair et al. (2017). Hair et al. (2017) suggested that the composite reliability (CR) should be greater than 0.7 , and the value of Cronbach's alpha and roh_A close to 1.00 shows a superior consistency. Table 2 showed that the criteria for the internal consistency of the five constructs were satisfied. To ensure the convergent validity, the value of AVE should be greater than 0.5 which means that the construct is accountable for more than $50 \%$ of the items included in the proposed model. All latent variables achieve convergent validity, given that their AVEs surpass the 0.5 level (Table 2).

\begin{tabular}{lcccrr}
\hline & CR & Cronbach's alpha & roh_A & AVE & \\
\hline CI & 0.809 & 0.910 & 0.814 & 0.680 & \\
D-ATT & 0.771 & 0.781 & 0.813 & 0.627 & \\
E-SAT & 0.832 & 0.842 & 0.951 & 0.554 & Table 2. \\
PU & 0.830 & 0.819 & 0.756 & 0.620 & Construct reliability \\
EXPC & 0.838 & 0.921 & 0.716 & 0.721 & and AVE \\
\hline
\end{tabular}

\section{Evaluating the customers' dining attitudes}


EJMBE 30,2

\section{0}

Table 3.

Discriminant validity: Fornell and Lacker criteria
Table 3 showed the Fornell and Lacker criteria to demonstrate the discriminant validity. As per the suggestion of Fornell and Lacker (1981), we have compared the square root of AVE of every construct and the correlation of coefficients with the rest of constructs. According to Hair et al. (2017), the diagonal values (square root of AVE) must be higher than the offdiagonal values (the correlations among the variables) in the correlation matrix. Table 3 demonstrated that all the diagonal values were higher than the off-diagonal values. Thus, the results of the study confirmed the discriminant validity of the study constructs. Moreover, Hair et al. (2017) suggested that the factor loadings more than 0.50 are considered to be acceptable. Table 4 showed that all of the items in the each construct were ranged from 0.676 to 0.857 .

Table 5 showed the results of the model fit. The measurement model showed that the hypothesized five-factor model $\left(\chi^{2}=84.317, \mathrm{df}=55, \chi^{2} / \mathrm{df}=1.533, p<0.01, \mathrm{CFI}=0.986\right.$, $\mathrm{TLI}=0.981, \mathrm{RMSEA}=0.046, \mathrm{SRMR}=0.034$ ) had a better data fit. In addition, the structural model also demonstrated that the model fit indices ensured good structural fit $\left(\chi^{2}=149.466\right.$, $\mathrm{df}=60, \chi^{2} / \mathrm{df}=2.491, p<0.01, \mathrm{CFI}=0.959, \mathrm{TLI}=0.946, \mathrm{RMSEA}=0.067, \mathrm{SRMR}=0.052$ ).

\begin{tabular}{lccccc}
\hline Endogenous variables & CI & D-ATT & E-SAT & EXPC & PU \\
\hline CI & 0.825 & & & & \\
D-ATT & 0.516 & 0.792 & & & \\
E-SAT & 0.529 & 0.631 & 0.849 & & \\
EXPC & 0.661 & 0.694 & 0.655 & 0.744 & 0.787 \\
PU & 0.643 & 0.592 & 0.631 & 0.714 & 0.75 \\
\hline
\end{tabular}

\begin{tabular}{lccccc}
\hline & CI & D-ATT & E-SAT & EXPC & PU \\
\hline CI1 & 0.805 & 0.435 & 0.414 & 0.587 & 0.513 \\
CI2 & 0.843 & 0.419 & 0.457 & 0.508 & 0.546 \\
D-ATT1 & 0.256 & 0.773 & 0.309 & 0.415 & 0.386 \\
D-ATT2 & 0.551 & 0.811 & 0.629 & 0.674 & 0.546 \\
E-SAT1 & 0.351 & 0.266 & 0.841 & 0.500 & 0.464 \\
E-SAT2 & 0.543 & 0.198 & 0.857 & 0.692 & 0.604 \\
EXPC1 & 0.485 & 0.578 & 0.390 & 0.775 & 0.553 \\
EXPC2 & 0.478 & 0.527 & 0.504 & 0.746 & 0.553 \\
EXPC3 & 0.548 & 0.520 & 0.573 & 0.775 & 0.558 \\
EXPC4 & 0.461 & 0.424 & 0.424 & 0.676 & 0.452 \\
PU1 & 0.498 & 0.206 & 0.517 & 0.471 & 0.808 \\
PU2 & 0.266 & 0.477 & 0.530 & 0.003 & 0.803 \\
PU3 & 0.448 & 0.376 & 0.433 & 0.506 & 0.750 \\
& & & & &
\end{tabular}

\begin{tabular}{lrcccccr}
\hline Models & \multicolumn{1}{c}{$\chi^{2}$} & $\mathrm{df}$ & $\chi^{2} / \mathrm{df}$ & CFI & TLI & RMSEA & SRMR \\
\hline Measurement Model & 84.317 & 55 & 1.533 & 0.986 & 0.981 & 0.046 & 0.034 \\
Structural Model & 149.466 & 60 & 2.491 & 0.959 & 0.946 & 0.067 & 0.052
\end{tabular}

Table 5. Note(s): $\mathrm{CFI}=$ Comparative Fit Index; TLI = Tucker-Lewis Index; RMSEA = Root Mean Square Error of The results of model fit Approximation; SRMR = Standardized Root Mean Square Residual 


\subsection{The structural model}

According to the suggestion of Hair et al. (2017), the structural model was verified by the coefficient of determinations (squared multiple correlations, $R^{2}$ ), the strength of the effect $\left(f^{2}\right)$ and the significance level of path coefficient. Bootstrapping (5,000 resamples) was used to generate $t$-statistics and confidence intervals. Figure 2 showed the coefficient of determinations $\left(R^{2}\right)$. E-SAT attains the largest explained variance $(0.679)$, whereas CI attains the lowest explained variance (0.331). According to Chin (1998) and Henseler et al. (2015), we tested the effect sizes (Cohen $f^{2}$ value) for analyzing the significance of the strength of effect size for the independent variables. Table 5 showed that all $f^{2}$ values were well above the base level of 0.02 .

The results of the path coefficient showed that $\operatorname{EXPC}(\beta=0.553, p<0.000)$ and $\mathrm{PU}(\beta=0.198, p<0.000)$ positively influenced D-ATT (Table 6). Thus, H1 and H2 were supported. Moreover, D-ATT $(\beta=0.861, p<0.000)$ also had a positive effect on customers' E-SAT. Hence, H3 was also supported. Finally, the path coefficient results showed that ESAT $(\beta=0.529, p<0.000)$ had a positive impact on continuance intention to use MFOAs. Therefore, H4 was accepted. Finally, we have computed the standardized root mean square residual (SRMR) of our model as the root mean square discrepancy between the correlations observed and the model-implied correlations (Henseler et al., 2016). Our research model achieves an SRMR of 0.043. The structural model of the study is depicted in Figure 2.

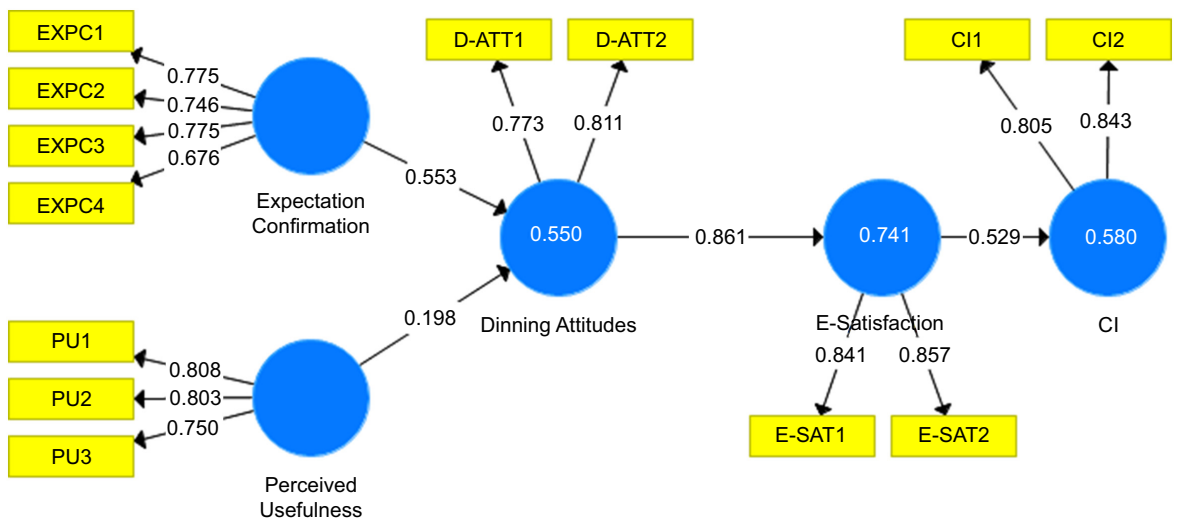

\begin{tabular}{|c|c|c|c|c|c|c|c|c|}
\hline Hypotheses & Relationship & $\begin{array}{l}\text { Path } \\
\text { coefficient }\end{array}$ & $\begin{array}{c}\text { SD } \\
\text { (STDEV) }\end{array}$ & $\begin{array}{c}T \text { statistics } \\
(\mid \mathrm{O} / \\
\text { STDEV|) }\end{array}$ & $\begin{array}{c}p \\
\text { values }\end{array}$ & $\begin{array}{l}\text { Strength of } \\
\text { effect }\left(f^{2}\right)\end{array}$ & Decision & \\
\hline $\mathrm{H} 1$ & $\begin{array}{l}\mathrm{EXPC} \rightarrow \mathrm{D}- \\
\mathrm{ATT}\end{array}$ & 0.553 & 0.072 & 7.710 & 0.000 & 0.300 & Supported & \\
\hline $\mathrm{H} 2$ & $\begin{array}{l}\mathrm{PU} \rightarrow \mathrm{D}- \\
\mathrm{ATT}\end{array}$ & 0.198 & 0.070 & 2.807 & 0.005 & 0.038 & Supported & \\
\hline H3 & $\begin{array}{l}\text { D-ATT } \rightarrow \text { E- } \\
\text { SAT }\end{array}$ & 0.861 & 0.036 & 24.059 & 0.000 & 2.856 & Supported & $\begin{array}{r}\text { The results of path } \\
\text { coefficient and }\end{array}$ \\
\hline $\mathrm{H} 4$ & E-SAT $\rightarrow$ CI & 0.529 & 0.086 & 6.146 & 0.000 & 0.389 & Supported & strength of effect $\left(f^{2}\right)$ \\
\hline
\end{tabular}

Evaluating the customers' dining attitudes

Figure 2. The structural model 
EJMBE

30,2

\section{Discussion}

The study aimed to analyze the hypothetical relationships among perceived usefulness, confirmation, attitudes, satisfaction and continuance intention using MFOAs during the COVID-19 pandemic period in Bangladesh. The results of the path coefficient analysis confirmed the four hypotheses of this study.

In hypothesis 1, we predicted that EXPC positively influenced D-ATT. As per our prediction, we found support in favor of the hypothesis. This finding suggested that EXPC was considered as one of the essential determinants predicting D-ATT of Bangladeshi customers. In the ECT model, Bhattacherjee (2001) provides the debates on varying and conflicting conceptualizations of the satisfaction construct. Some authors view satisfaction as synonymous with attitude and emotion. While attitude is an emotion, others argue that satisfaction is an evaluation of the emotion (Hung et al., 2007). This study included and tested attitude and satisfaction in a single study and found that EXPC as an antecedent of D-ATT.

In hypothesis 2 , this study posited and found that PU had a positive impact on D-ATT. This finding is analogous with the study of Nguyen et al. (2019) and Alagoz and Hekimoglu (2012), who identified PU as an antecedent of customers' attitudes to order food using technology. Roh and Park (2018) found that PU has positively influence customers' attitude in case $\mathrm{O} 2 \mathrm{O}$ food delivery services in South Korea, considering the moderating role of moral obligation in meal preparation. Moreover, the positive relationship between PU and CI was found by Okumus and Bilgihan (2014) Bhattacherjee (2001) and Suhartanto et al. (2019) in context of different forms of IS usage. The advantageous features of MFOAs motivate customers to show a positive attitude towards purchasing and ordering foods through mobile apps.

Hypothesis 3 predicted that D-ATT might impact E-SAT. The result of the study found that D-ATT significantly influences E-SAT. Previous studies focused on the role of attitude in explaining satisfaction (Butt and Aftab, 2013; Currás-Pérez et al., 2013). Currás-Pérez et al. (2013) mentioned that a positive attitude in case of using the social networking sites is considered as one of the powerful predictors of satisfaction. In this regard, Oliver (1980) mentioned satisfaction as the assessment of the customers' attitudes before actual consumption. Moreover, Hunt (1977) emphasized that attitude is assumed to be an emotion and satisfaction as the assessment of that particular emotion. Thus, the customer's positive attitudes toward MFOAs lead to E-SAT.

In hypothesis 4, the current study hypothesized that E-SAT had a positive influence on CI. When customers are pleased with the service of MFOAs, customers are more likely to have a continued intention to use MFOAs. This finding is associated with the study of Alalwan (2020), who found that customer satisfaction with MFOAs is positively related to CI. Moreover, Christodoulides and Michaelidou (2010) analogized the same relationship in case of online retailing business in UK and found that the satisfied customers of online shopping are more likely to use the same systems repeatedly. Accordingly, the intention to reuse can strongly be predicted by the extent to which a customer is pleased or satisfied with the IS's prior experience.

\subsection{Theoretical contributions}

This study has three main theoretical contributions. First, the current research is the first empirical study that has examined the ECT theory in the context of MFOAs incorporating consumers' dinning attitudes toward MFOAs from TAM. Consequently, the study findings significantly contribute to the emerging literature on MFOAs by exploring the influence of the factors of customers' perceived usefulness, confirmation, attitudes, e-satisfaction and continuous usage intention. Also, the present study examined the behavioral intention of users of MFOAs in a culturally diverse country, like Bangladesh. Bangladesh is facing a 
profound digitization transition in recent years, and the MFOAs industry in the country is expected to expand as well. Moreover, this research is one of the first that investigates the behavioral intention of Bangladeshi MFOAs users. Finally, this study undertook a large sample to measure the study model. Most of the previous studies focused on a small sample in the field of MFOAs.

\section{Evaluating the customers dining attitudes}

\subsection{Practical contributions}

In addition to theoretical contributions, this study provides a practical understanding of the factors that should be considered in designing and marketing MFOAs. MFOAs could be the ideal way to educate users and connect restaurants by providing ease-of-access features such as complete foods, nutrition details, map directions, direct telephone calls, online coupons and notifications. For example, it should allow users to identify the menus with calories. By using different nutritional food apps, consumers are now more aware of the nutritional benefit of different foods. This could presumably lead to the problem of avoiding unhealthy menu items by the customers, so MFOAs should collaborate with restaurants to include nutritional information of each food item. MFOAs should convince restaurants to avoid offering unhealthy food and include healthier food options. Besides, designing apps to facilitate healthy eating may create long-term customer relationships. To enhance the perceived usefulness, MFOAs should improve services that allow users to monitor their calorie intake, maintain records of food consumed, and track the feedback of other users. MFOAs can enable users to fix daily value targets for daily calorie, fat, fiber, carbs, and protein and assist users in monitoring their consumption (Okumus and Bilgihan, 2014). MFOAs can also provide information related to boosting immunity and the time of exercise required to burn the calorie intake since, during the COVID-9 pandemic period, it is essential to take care of the user's health.

Perceived confirmation was the most significant determinants explaining users' attitude using MFOAs. To help users confirm their expectations, apps service providers need to understand better what they expect of MFOAs by conducting regular needs assessment and evaluating how the MFOAs are currently meeting those expectations. The results reveal a greater effect of e-satisfaction on continuance intentions. MFOA operators should aim to strengthen consumers' e-satisfaction because this will lead to more continuance intentions to use MFOAs. This means that MFOA operators must take measures concerning variables such as perceived confirmation and usefulness. Additional financial incentives (e.g. price discounts, quantity discounts, and points) and loyalty schemes should be implemented for active users. Loyal customers should be given extra benefits since they play an essential role in promoting sales by attracting and recommending new customers. To make the platform more useful, MFOA providers may link mobile payment service providers for giving extra cash discount for payment through mobile payment service.

The FMOAs experienced substantial attention from Bangladeshi users. FMOAs operators should, therefore, make more efforts to promote this market. The expectations of new users are generally determined by previous users' experience shown in the review systems. As the number of customers evaluating and reviewing their experiences with MFOAs is significant, MFOA operators can encourage users to rate and evaluate, and make the assessment and evaluation process more comfortable. All customers' comments and reviews should also be monitored to ensure that reviews are updated, appropriate, and reliable so that other customers can regard them as a valuable information resource. The online rating system should also be designed to make it easier for customers to find top-notch restaurants (Alalwan, 2020).

MFOAs service providers need to concentrate more on promotional campaigns to persuade consumers that MFOAs takes minimum time and effort compared with 
EJMBE 30,2

\section{4}

conventional means of ordering food that include the physical presence in restaurants or telephone calls. MFOAs should pay much attention to delivery accuracy and speed since the users relate the delivery speed with the usefulness of the MFOAs. In addition, frequent maintenance is necessary to ensure the reliability and quality of the platform of MFOAs to ensure that customers can easily and reliably access and order food via MFOAs. The technical support and services required for customers' access and efficient use of MFOAs should also be taken into account. The MFOAs should provide the customer care service for immediate problem solving to make the platform effective. The service providers should constantly search for ways to innovate new features to district their platform of MFOAs from the competitors (Okumus et al., 2018).

The usual service of MFOAs was hampered in the interim period of COVID-19 due to the limited operations of most restaurants in Bangladesh. Customers should be assured that the safety measures are undertaken while delivering the food. Restaurants managers should focus on online sales through MFOAs during the pandemic period since social distancing is a key strategy to manage COVID-19. Given the limited physical presence of customers at premises and diminished customer flows, restaurants might face recovery problems, especially as they usually have little liquidity and profit margins. With fewer resources such as staff and raw materials, restaurant managers should balance their operational activities, emphasizing the survival with marginal profit. MFOA service providers should provide the necessary supports to the restaurants with constraints to cope with the emergent situation.

\subsection{Limitation and further study}

Like most studies, this study is not free from limitations. First, this study is cross-sectional nature; thus, the study variables' causal relationships cannot be confirmed. A longitudinal study may be conducted in the future to reveal causal relationships. Second, since the data were collected from a single source, i.e. from the customers, the common method variance (CMV) might impact the study. Although the CMV test results showed the absence of CMV problem, the future study may collect data from different periods. Third, the data were collected from Bangladesh during the COVID-19 pandemic period, which limits the generalization of the study results to other countries.

Since the present study focused on the expectation-confirmation theory and technology acceptance model in MFOAs, further study may incorporate the Theory of Acceptance and Use of Technology (UTAUT2) to unveil the study relationships. Future research should explore whether there are specific mobile application functions that would make consumers who are currently ambivalent about apps intend to use them, or whether other factors such as perceived ease of use or price values, which were not fully explored in this study, are more important. Finally, additional research should investigate how a combination of mobile touch points (e.g. a coupon for a free item, mobile ordering and mobile payment) influences food purchasing decisions. It will be interesting if the future study extends the current study by contrasting the picture with other developing countries in South Asia (e.g. India, Pakistan).

\section{References}

Alagoz, S.M. and Hekimoglu, H. (2012), "A study on TAM: analysis of customer attitudes in online food ordering system", Procedia - Social and Behavioral Sciences, Vol. 62, pp. 1138-1143.

Alalwan, A.A. (2020), "Mobile food ordering apps: an empirical study of the factors affecting customer e-satisfaction and continued intention to reuse", International Journal of Information Management, Vol. 50 No. 2020, pp. 28-44. 
Ajzen, I. (1991), "Theory of planned behavior", Organigational Behavior and human cecission process, Vol. 50 No. 2, pp. 179-211.

Anderson, R.E. and Srinivasan, S.S. (2003), "E-satisfaction and e-loyalty: a contingency framework", Psychology and Marketing, Vol. 20 No. 2, pp. 123-138.

Anderson, E.W. and Sullivan, M.S. (1993), "The antecedents and consequences of customer satisfaction for firms", Marketing Science, Vol. 12 No. 2, pp. 125-143.

Baabdullah, A.M., Alalwan, A.A., Rana, N.P., Patil, P. and Dwivedi, Y.K. (2019), “An integrated model for m-banking adoption in Saudi Arabia”, International Journal of Bank Marketing, Vol. 37 No. 2, pp. $452-478$.

Bhattacherjee, A. (2001), "Understanding information system continuance: an expectation confirmation model”, MIS Quarterly, Vol. 25, pp. 351-370.

Brislin, R. (1976), “Comparative research methodology: cross-cultural studies”, International Journal of Psychology, Vol. 11 No. 3, pp. 215-229.

BRTC (2020), "Mobile phone subscribers in Bangladesh February, 2020 | BTRC", [online], available at: www.btrc.gov.bd http://www.btrc.gov.bd/content/mobile-phone-subscribers-bangladeshfebruary-2020.

Butt, M.M. and Aftab, M. (2013), "Incorporating attitude towards Halal banking in an integrated service quality, satisfaction, trust and loyalty model in online Islamic banking context", The International Journal of Bank Marketing, Vol. 31 No. 1, pp. 6-23.

Carlson, J., Rahman, M.M., Taylor, A. and Voola, R. (2019), "Feel the VIBE: examining value-in-thebrand-page-experience and its impact on satisfaction and customer engagement behaviours in mobile social media”, Journal of Retailing and Consumer Services, Vol. 46, pp. 149-162.

Chin, W.W. (1998), “Commentary: issues and opinion on structural equation modeling”, MIS Quarterly, Vol. 22 No. 1, available at: https://www.jstor.org/stable/249674.

Cho, M., Bonn, M.A. and Li, J.J. (2019), "Differences in perceptions about food delivery apps between single-person and multi-person households", International Journal of Hospitality Management, Vol. 77, pp. 108-116.

Christodoulides, G. and Michaelidou, N. (2010), "Shopping motives as antecedents of e-satisfaction and e-loyalty", Journal of Marketing Management, Vol. 27 Nos 1-2, pp. 181-197.

Citi Velocity (2020), "How covid-19 is impacting online food delivery platforms", available at: https:// www.citivelocity.com/citigps/how-covid-19-is-impacting-online-food-delivery-platforms/ (accessed 27 June 2020).

Currás-Pérez, R., Ruiz-Mafé, C. and Sanz-Blas, S. (2013), "Social network loyalty: evaluating the role of attitude, perceived risk and satisfaction”, Online Information Review, Vol. 37 No. 1, pp. 61-82.

Davis, F.D., Bagozzi, R.P. and Warshaw, P.R. (1989), "User acceptance of computer technology: a compairsio of two theoritical models", Maagement science, Vol. 35 No. 8, pp. 982-1003.

Faraoni, M., Rialto, R., Zollo, L. and Pellicelli, A.C. (2019), "Exploring e-Loyalty Antecedents in B2C e-Commerce: empirical results from Italian grocery retailers", British Food Journal, Vol. 12 No. 2, pp. 574-589.

Fornell, C. and Larcker, D.F. (1981), "Evaluating structural equation models with unobservable variables and measurement error", Journal of Marketing Research, Vol. 18 No. 1, p. 39, doi: 10. $2307 / 3151312$.

Future Startup (2020), "The State of online food Delivery in Bangladesh at the Beginning of 2020: subsidies make true demand hard to gauge", available at: https:/futurestartup.com/2020/02/04/ online-food-delivery-in-bangladesh-subsidies-make-true-demand-hard-to-gauge/ (accessed 18 June 2020).

Gössling, S., Scott, D. and Hall, C.M. (2020), "Pandemics, tourism and global change: a rapid assessment of COVID-19", Journal of Sustainable Tourism, Vol. 29 No. 1, pp. 1-20.

\section{Evaluating the customers' dining attitudes}


EJMBE 30,2

\section{6}

Hair, J.F., Hult, G.T.M., Ringle, C.M. and Sarstedt, M. (2017), A Primer on Partial Least Squares Structural Equation Modeling (PLS-SEM), 2nd ed., Sage, Thousand Oaks, CA.

Hasan, M. (2020), "Restaurants' if tar season salvaged by food delivery platforms", [online], The Daily Star, available at: https://www.thedailystar.net/business/news/restaurants-iftar-seasonsalvaged-food-delivery-platforms-1898902 (accessed 11 May 2020).

Henseler, J., Ringle, C.M. and Sarstedt, M. (2015), "A new criterion for assessing discriminant validity in variance-based structural equation modeling", Journal of the Academy of Marketing Science, Vol. 43 No. 2015, pp. 115-135.

Henseler, J., Hubona, G. and Ray, P.A. (2016), "Using PLS path modeling in new technology research: updated guidelines", Industrial Management and Data Systems, Vol. 116 No. 1, pp. 2-20, doi: 10. 1108/IMDS-09-2015-0382.

Hospitality Insights (2020), "Covid-19 delivery services", available at: https://hospitalityinsights.ehl. edu/covid-19-delivery-services (accessed 27 June 2020).

Hung, M.C., Hwang, H.G. and Hsieh, T.C. (2007), "An exploratory study on the continuance of mobile commerce: an extended expectation-confirmation model of information system use", International Journal of Mobile Communications, Vol. 5 No. 4, pp. 409-422.

Hunt, H.K. (1977), "CS/D - overview and future research directions", in Hunt, H.K. (Ed.), Conceptualization and Measurement of Consumer Satisfaction and Dissatisfaction, Marketing Science Institute, Cambridge, MA, pp. 455-88.

Izzati, B.M. (2020), "Analysis of customer behavior in mobile food ordering application using UTAUT model (case study: GoFood application)", International Journal of Innovation in Enterprise System, Vol. 4 No. 1, pp. 23-34.

Joo, S. and Choi, N. (2016), "Understanding users' continuance intention to use online library resources based on an extended expectation-confirmation model", The Electronic Library, Vol. 34 No. 4, pp. 554-571.

Kang, J. and Namkung, Y. (2019), "The role of personalization on Continuance Intention in food service mobile apps: a privacy calculus perspective", International Journal of Contemporary Hospitality Management, Vol. 31 No. 2, pp. 734-752, doi: 10.1108/IJCHM-12-2017-0783.

Kapoor, A.P. and Vij, M. (2018), “Technology at the dinner table: ordering food online through mobile apps", Journal of Retailing and Consumer Services, Vol. 43, pp. 342-351.

Karahanna, E., Straub, D.W. and Chervany, N.L. (1999), "Information technology adoption across time: a cross-sectional comparison of pre-adoption and post-adoption beliefs", Management Information Systems Quarterly, Vol. 23 No. 2, pp. 183-213.

Khan, M.J. and Khan, M.R. (2020), "A bleak Baishakh for restaurants”, [online], The Daily Star, available at: https://www.thedailystar.net/city/news/bleak-baishakh-restaurants-1892812.

Kim, D.J. (2010), "An investigation of the effect of online consumer trust on expectation, satisfaction, and post-expectation", Information Systems and E-Business Management, Vol. 10 No. 2, pp. 219-240.

Koiri, S.K., Mukherjee, S. and Dutta, S. (2019), "A study on determining the factors impacting consumer perception regarding the online food delivery apps in guwahati", GIS Business, Vol. 14 No. 6, available at: https://ssrn.com/abstract $=3546933$.

Lee, S.W., Sung, H.J. and Jeon, H.M. (2019), "Determinants of continuous intention on food delivery apps: extending UTAUT2 with information quality", [online], Sustainability, Vol. 11 No. 11, p. 3141, available at: https://www.mdpi.com/2071-1050/11/11/3141/htm (accessed 2 December 2019).

Limayem, M. and Cheung, C.M.K. (2008), "Understanding information systems continuance: the case of Internet-based learning technologies", Information and Management, Vol. 45 No. 4, pp. 227-232.

Lin, C.S., Wu, S. and Tsai, R.J. (2005), "Integrating perceived playfulness into expectation-confirmation model for web portal context", Information and Management, Vol. 42 No. 5, pp. 683-693. 
Lindell, M.K. and Whitney, D.J. (2001), "Accounting for common method variance in cross-sectional research designs”, Journal of Applied Psychology, Vol. 86 No. 1, pp. 114-121, doi: 10.1037/00219010.86.1.114.

Mundy, S. (2018), "Compitition heats up in online food delivery market", Financial Times, available at: https://www.ft.com/content/365617e6-f239-11e8-ae55-df4bf40f9d0d (accessed 28 March 2020).

Nguyen, T.T.H., Nguyen, N., Nguyen, T.B.L., Phan, T.T.H., Bui, L.P. and Moon, H.C. (2019), "Investigating consumer attitude and intention towards online food purchasing in an emerging economy: an extended TAM approach", Foods, Vol. 8 No. 11, p. 576.

Okumus, B. and Bilgihan, A. (2014), "Proposing a model to test smartphone users' intention to use smart applications when ordering food in restaurants", Journal of Hospitality and Tourism Technology, Vol. 5 No. 1, pp. 31-49.

Okumus, B., Ali, F., Bilgihan, A. and Ozturk, A.B. (2018), "Psychological factors influencing customers' acceptance of smartphone diet apps when ordering food at restaurants", International Journal of Hospitality Management, Vol. 72, pp. 67-77.

Oliver, R.L. (1977), "Effect of expectation and disconfirmation on postexposure product evaluations: an alternative interpretation”, Journal of Applied Psychology, Vol. 62 No. 4, pp. 480-486, doi: 10. 1037/0021-9010.62.4.480.

Oliver, R.L. (1980), "A cognitive model of the antecedents and consequences of satisfaction decisions", Journal of Marketing Research, Vol. 17 No. 4, pp. 460-469.

Oliver, R.L. (1988), "Response determinants in satisfaction judgments", The journal of customer research, Vol. 14, pp. 495-508.

Pigatto, G., Machado, J.G.D.C.F., Negreti, A.D.S. and Machado, L.M. (2017), "Have you chosen your request? Analysis of online food delivery companies in Brazil", British Food Journal, Vol. 119 No. 3, pp. 639-657.

Podsakoff, P.M. and Organ, D.W. (1986), "Self-reports in organizational research: problems and prospects", Journal of Management, Vol. 12 No. 4, pp. 531-544.

Qazi, A., Tamjidyamcholo, A., Raj, R.G., Hardaker, G. and Standing, C. (2017), “Assessing consumers' satisfaction and expectations through online opinions: expectation and disconfirmation approach”, Computers in Human Behavior, Vol. 75, pp. 450-460.

Ray, A., Dhir, A., Bala, P.K. and Kaur, P. (2019), "Why do people use food delivery apps (FDA)? Auses and gratification theory perspective", Journal of Retailing and Consumer Services, Vol. 51, pp. 221-230.

Roh, M. and Park, K. (2018), "Adoption of O2O food delivery services in South Korea: the moderating role of moral obligation in meal preparation", International Journal of Information Management, Vol. 47, pp. 262-273.

See-Kwong, G., Soo-Ryue, N., Shiun-Yi, W. and Lily, C. (2017), "Outsourcing to online food delivery services: perspective of F\&B business owners", [online], The Journal of Internet Banking and Commerce, Vol. 22 No. 2, pp. 1-18, available at: http://www.icommercecentral.com/openaccess/outsourcing-to-online-food-delivery-services-perspective-of-fb-business-owners.php? aid $=86136$.

Shah, A.M., Yan, X., Shah, S.A.A. and Ali, M. (2020), "Customers' perceived value and dining choice through mobile apps in Indonesia", Asia Pacific Journal of Marketing and Logistics, ahead-ofprint No. ahead-of-print. doi: 10.1108/APJML-03-2019-0167.

Shareef, M.A., Archer, N. and Dwivedi, Y.K. (2012), "Examining adoption behavior of mobile government", Journal of Computer Information Systems, Vol. 53 No. 2, pp. 39-49.

Shaw, S.H. (2016), "Uncliping our wings: ways forward in qualittive research in sport management", Sport Management Review, Vol. 19, pp. 255-265.

Spyridou, A. (2017), "Perceived service quality and customer revisiting intention: the case of 'all you can eat' Asian restaurants in southern taiwan", Journal of Tourism, Heritage and Services Marketing, Vol. 3 No. 2, pp. 30-38.

\section{Evaluating the customers' dining attitudes}

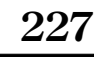


EJMBE 30,2

\section{8}

Statista Report (2018), "eServices Report 2019 - online food delivery”, [online], Statista, available at: https:/www.statista.com/study/40457/food-delivery/.

Suhartanto, D., Marwansyah, M., Muflih, M., Najib, M.F. and Faturohman, I. (2019), "Loyalty formation toward Halal food", British Food Journal, Vol. 122 No. 1, pp. 48-59.

Tang, A.K.Y. (2019), "A systematic literature review and analysis on mobile apps in m-commerce: implications for future research", Electronic Commerce Research and Applications, Vol. 37, 100885, doi: 10.1016/j.elerap.2019.100885.

Thakur, R. and Srivastava, M. (2014), “Adoption readiness, personal innovativeness, perceived risk and usage intention across customer groups for mobile payment services in India", Internet Research, Vol. 24 No. 3, pp. 369-392, doi: 10.1108/intr-12-2012-0244.

Tran, L.T.T., Pham, L.M.T. and Le, L.T. (2019), "E-satisfaction and continuance intention: the moderator role of online ratings", International Journal of Hospitality Management, Vol. 77, pp. 311-322.

Trivedi, S.K. and Yadav, M. (2018), "Predicting online repurchase intentions with E-satisfaction as mediator: a study on Gen Y", VINE Journal of Information and Knowledge Management Systems, Vol. 48 No. 3, pp. 427-447.

UN (2020), "Bangladesh country-profile", [online], available at: http://data.un.org/CountryProfile. aspx/_Images/CountryProfile.aspx?crName=Bangladesh (accessed 19 July 2020).

Wang, Y.S., Tseng, T.H., Wang, W.T., Shih, Y.W. and Chan, P.Y. (2019), "Developing and validating a mobile catering app success model", International Journal of Hospitality Management, Vol. 7, pp. 19-30.

Worldometers (2020), "Bangladesh corona case”, [Online], available at: https://www.worldometers.info/ coronavirus/country/bangladesh/ (accessed 19 July 2020).

$\mathrm{Xu}, \mathrm{X}$. and Huang, Y. (2019), "Restaurant information cues, Diners' expectations, and need for cognition: experimental studies of online-to-offline mobile food ordering", Journal of Retailing and Consumer Services, Vol. 51, pp. 231-241, doi: 10.1016/j.jretconser.2019.06.010.

Yang, S., Lin, S., Carlson, J.R. and Ross, W.T. Jr (2016), “Brand engagement on social media: will firms' social media efforts influence search engine advertising effectiveness?”, Journal of Marketing Management, Vol. 32 Nos 5-6, pp. 526-557.

Yang, S., Asaad, Y. and Dwivedi, Y. (2017), "Examining the impact of gamification on intention of engagement and brand attitude in the marketing context", Computers in Human Behavior, Vol. 73, pp. 459-469.

Yeo, V.C.S., Goh, S.K. and Rezaei, S. (2017), "Consumer experiences, attitude and behavioral intention toward online food delivery (OFD) services", Journal of Retailing and Consumer Services, Vol. 35, pp. 150-162.

\section{Further reading}

Bhattacherjee, A.P. Perols, J. and Sanford, C. (2008), "Information technology continuance: a theoretic extension and empirical test”, Journal of computer Information, Vol. 49 No. 1, pp. 17-26.

Podsakoff, P.M., MacKenzie, S.B., Lee, J.Y. and Podsakoff, N.P. (2003), "Common method biases in behavioral research: a critical review of the literature and recommended remedies",Journal of Applied Psychology, Vol. 88 No. 5, pp. 879-903. 
Appendix

Constructs and source

Expectations' Confirmation (EXPC)

Bhattacherjee (2001)

Joo and Choi (2016)

$\operatorname{Kim}(2009)$

Perceived Usefulness (PU)

Okumus and Bilgihan (2014), Davis et al. (1989)

Dining Attitudes (D-ATT)

Cho et al. (2019)

E-Satisfaction (E-SAT)

Alalwan (2020), Anderson and Srinivasan (2003)

Continuance Intention (CI)

Alalwan (2020)

Faraoni et al. (2019)

Lee et al. (2019)
Measurement items

EXP1: My experience with using MFOA was better than what I expected

EXP2: The service level provided by MFOA was better than what I expected

EXP3: Overall, most of my expectations from using MFOA were confirmed

EXP4: The expectations that I have regarding MFOAs were correct

PU1: MFOA can be useful in managing my food orders

PU2: The app can be beneficial to me

PU3: The app can be valuable to my diet

D-ATT1: Using the MFOA is useful

D-ATT2: I am strongly in favor of ordering food through MFOA

E-SAT1: I am generally pleased with MFOA

E-SAT 2: My choice to purchase from MFOA was a wise one

CI1: I intend to continue using MFOA rather than discontinue its use

CI2: If I have an opportunity, I will order food through MFOA
Table A1.

Measurement items

\section{Corresponding author}

Md. Al Amin can be contacted at: alamin.bsmrstu21@gmail.com

For instructions on how to order reprints of this article, please visit our website:

www.emeraldgrouppublishing.com/licensing/reprints.htm

Or contact us for further details: permissions@emeraldinsight.com 